\title{
La naturaleza de la luz
}

\author{
Luis de la Peña
}

\section{Resumen}

En este artículo se da una introducción a la naturaleza de la luz a través primero de una breve revista a la larga batalla del hombre por alumbrarse de noche. Se examinan a continuación las dos respuestas básicas que se dieron históricamente a la pregunta sobre la naturaleza de la luz. La última parte trata sobre la influencia profunda de la física del siglo XX (la relatividad y mecánica cuántica) en nuestra concepción de la luz, para terminar, comentando sobre algunos temas relativos a nuestra percepción del color.

Palabras clave: partícula, onda, onda electromagnética, fotón, espectro.

\section{THE NATURE OF LIGHT}

\begin{abstract}
This article starts with a brief introduction to the nature of light through a short review of the long battle of human beings to produce some light at night. We then examine the two basic answers given historically to the question about the nature of light. In the last section we recall the influence that the physics of the 20th Century (relativity and quantum mechanics) has had on our conception of light, to conclude with some comments about our perception of color.
\end{abstract}

Key words: particle, wave, electromagnetic wave, photon, spectrum. 


\section{Luis de la peña}

Físico mexicano, investigador emérito del Instituto de Física de la UNAM. Es ingeniero en Comunicaciones Eléctricas y Electrónica por la Escuela Superior de Ingeniería Mecánica y Eléctrica del Instituto Politécnico Nacional. Obtuvo el doctorado en Ciencias Físico-Matemáticas en la Universidad Estatal Lomonosov de Moscú, Rusia. En la UNAM, es profesor de la Facultad de Ciencias e investigador del Instituto de Física. Pertenece al Sistema Nacional de Investigadores (SNI), también como Investigador Emérito. Su campo de especialidad es la física teórica y los fundamentos de la mecánica cuántica. Además, se ha destacado como un gran divulgador de la ciencia. De la caracterización de la dinámica cuántica pasó a la búsqueda de sus orígenes.

\section{La naturaleza de la luz}

Tenemos la luz tan a la mano, tan cercana, que podríamos decir que la conocemos como a nuestra madre o a nuestro hermano. Pero en realidad, si analizamos con cuidado, veremos que empezamos a entender qué es la luz hace cosa de doscientos años, lo cual es relativamente poco si lo comparamos con la historia de la humanidad. Y si no sabíamos qué es la luz, tampoco podíamos explicar qué son y por qué se dan los colores. ¿Qué es la luz? ¿De dónde surgen

Imagen 1. Ios colores? Y en la luz blanca, ¿de qué manera se nos ocultan los matices que la componen?

No nos extrañaría que un niño de seis o siete años nos hiciera alguna de estas preguntas. Sorprendido, habría descubierto que no puede sujetar un poco de luz entre sus dedos, aunque siente el calor que ésta le dispensa. La realidad, sin embargo, es que la mayor parte de la gente no sabría contestar preguntas como éstas.

Mucho antes de interesarse en la naturaleza de la luz, a nuestros antepasados les preocupó aprender a producir luz, por razones que no es difícil comprender. En la Tierra, hace cuatro mil millones de años, sólo brillaban el Sol, la Luna y las estrellas. Desde entonces y hasta ahora el Sol es la fuente más 
importante de energía en nuestro planeta. Toda forma de vida en la Tierra depende de su presencia, directa o indirectamente. El Sol nos calienta e ilumina, hace que las plantas produzcan el oxígeno que respiramos y fabriquen nuestros alimentos y el de los animales.

Para vencer el frío y la oscuridad nuestros antepasados crearon fuentes de luz y calor. Durante cientos de miles de años el hombre de las cavernas sólo contó con fogatas y más tarde con antorchas para calentarse, iluminarse y alejar los peligros de la noche.

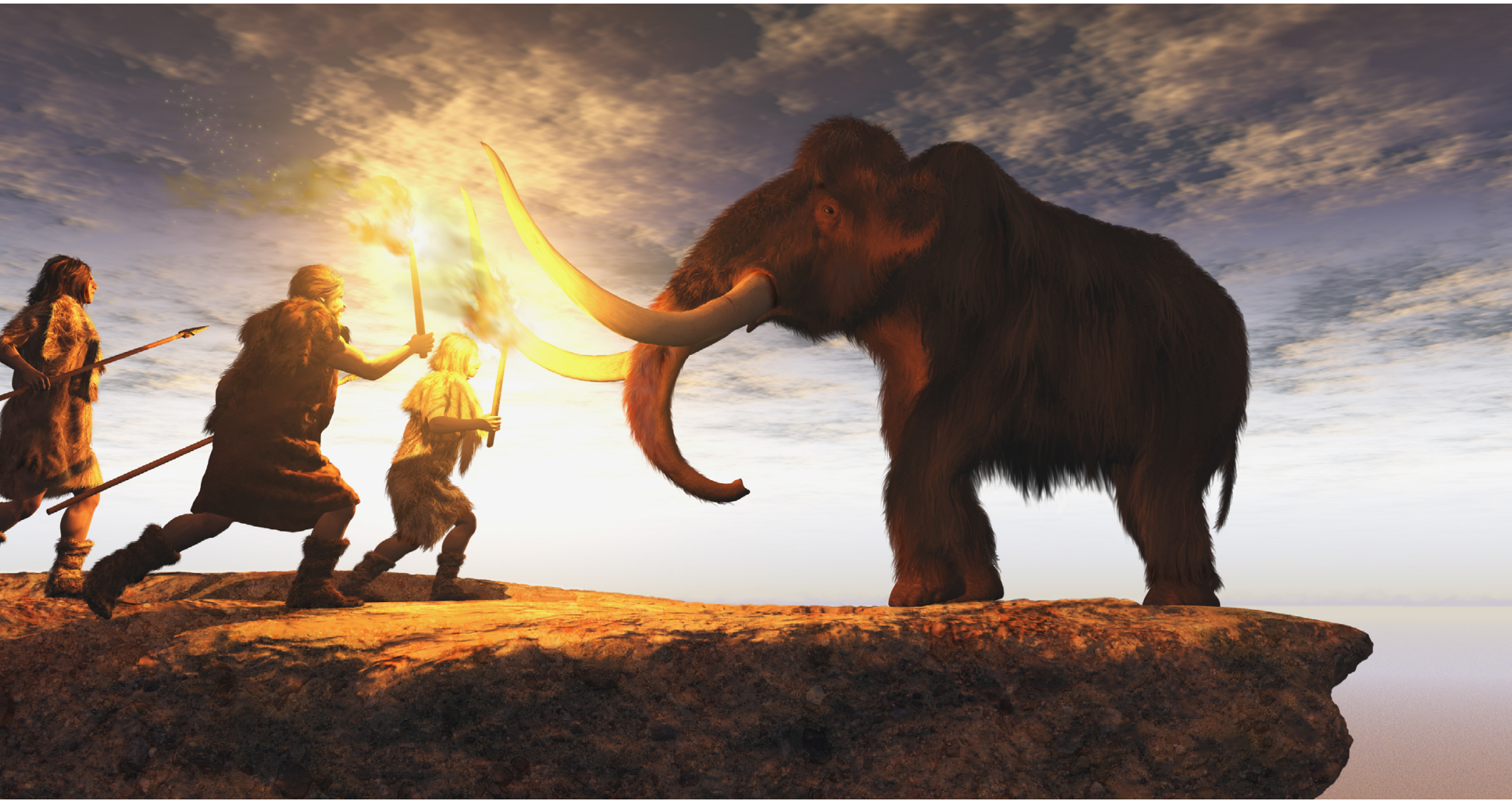

Imagen 2.

El Homo heidelbergensis comenzó a utilizar el fuego desde hace 1,4 millones de años.
Hace apenas 13000 años aparecieron las más primitivas lámparas de aceite de llama abierta, en conchas y recipientes similares. El progreso resultó lentísimo: apenas 500 años antes de la era común se inventaron en Roma las lámparas de aceite con recipiente de reserva -de barro, piedra o metal, simples o elegantes-. Algunas de ellas continúan en uso en lugares apartados, lo que significa más de 13000 años de servicio. Además del cuchillo o la flecha, ningún otro dispositivo iguala este éxito. Poco tiempo después apareció la vela de cera de abeja, la cual iluminó los grandes salones de baile de los palacios reales. Van ya 2500 años de fabricar velas de cera. El día de hoy se emplean en la decoración y ambientación, o para espantar olores o insectos. Su uso como fuentes de luz es ya muy menor y circunstancial. 


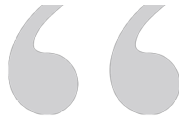

\section{¿Podemos decir hoy que ya} conocemos a cabalidad la luz? Ni tratándose de la luz ni de ningún otro asunto podemos decir que ya sabemos todo. Mucho hemos aprendido con el desarrollo de la ciencia y del conocimiento en general, lo que nos ha permitido aprender a hacer multitud de cosas, aparatos e instrumentos de toda índole.

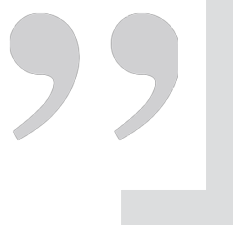

Transcurrieron siglos antes de que ocurriese otro acontecimiento importante en este terreno, pero ya no milenios. Fue así como en el siglo xvı Leonardo da Vinci dotó a la lámpara de aceite de una chimenea para aumentar su brillo y estabilidad. Hacia 1800 Humphrey Davy inventó en Inglaterra la lámpara de arco, en la que arden dos barras de carbón entre las que salta un arco eléctrico continuo. Fue la primera lámpara eléctrica, sólo que alimentada con las ineficientes baterías de la época, que se agotaban al cabo de unos minutos. Poco después, en 1814, apareció la lámpara de gas, que continuó iluminando las calles por casi un siglo, y en 1853 comenzaron a emplearse también lámparas de keroseno. Para entonces los faros de los puertos ya habían adoptado la lente de Fresnel (una lente convergente plana y ligera), lo que fue un paso importante para la seguridad de los barcos: un faro dotado con una lente de Fresnel señalaba con una luz más intensa los lugares de riesgo para la navegación. En todo ese tiempo las casas, los castillos y los palacios continuaron calentándose con leña producida con energía proveniente del sol.

Fue en 1879 cuando Thomas Edison (en Estados Unidos) y Joseph Swan (en Inglaterra) llegaron independientemente a un invento que transformó nuestra vida: la lámpara eléctrica incandescente, la que nosotros conocemos como foco, y que de inmediato comenzó a alumbrar casas y calles. A partir de ese momento la técnica de la iluminación artificial avanza a otro ritmo. Casi cada diez años se da un paso importante en la conquista de la luz para alumbrarnos. A finales del siglo xix llegó la luz de neón y de otros gases (y otros colores), producida al ionizarse el gas con la ayuda de una corriente eléctrica. Poco después se eleva la eficiencia de la lámpara incandescente por un factor de tres al llenarla con un gas inerte. En la década siguiente, la lámpara de sodio de baja presión, en la que la fuente de luz es vapor de sodio, se convirtió en indispensable para la seguridad en las carreteras. Diez años después se generalizó la lámpara fluorescente de mercurio por su alta eficiencia.

A mediados del siglo llegó la fibra óptica, eficaz transmisora y guía de la luz. La fibra óptica es para la luz lo que los cables de cobre han sido para la electricidad. Para 1960, el láser se convirtió en una realidad y hoy invade todos los laboratorios ópticos y nuestros hogares y bolsillos con los CD y DVD, los lectores de códigos de barras, etcétera. Las ciudades mejoraron su iluminación poco después por medio de la lámpara de sodio de alta presión, que resulta mucho más eficiente y económica que sus antecesoras. No tarda sino una década en aparecer la lámpara fluorescente pequeña, que pronto sustituye a las lámparas incandescentes 


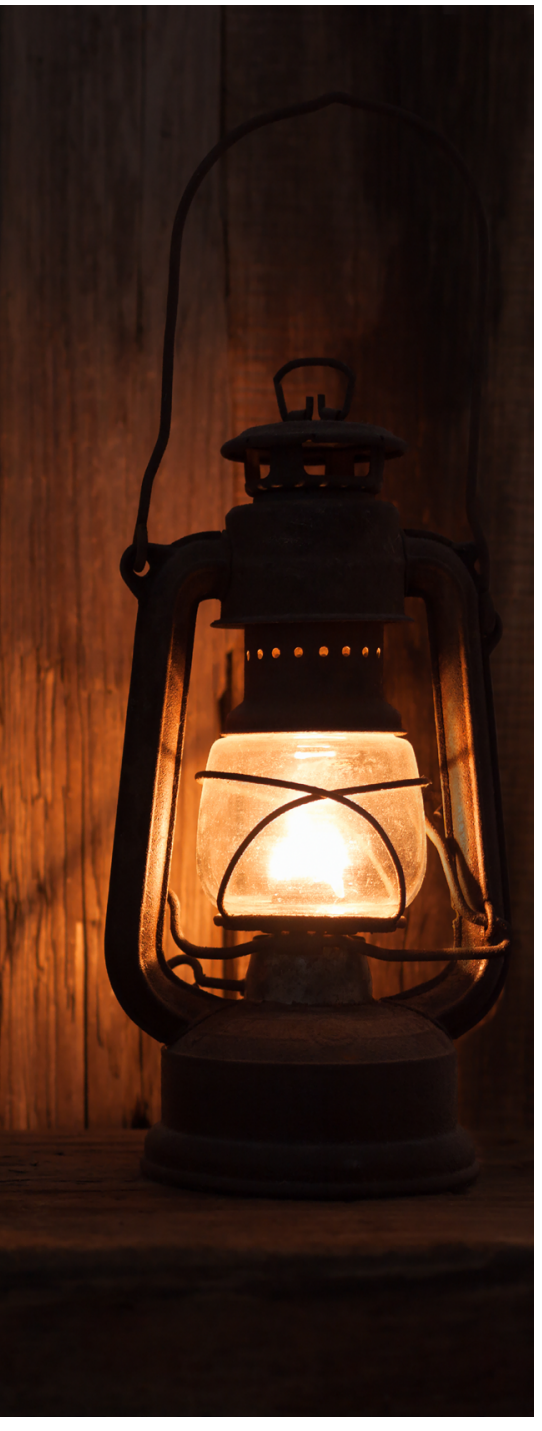

Imágenes 3, 4 y 5. Ejemplos de lámparas de aceite a lo largo del tiempo. Fuente: rootsimple.com, iStock. usuales por resultar tres veces más eficiente, pues no derrocha energía en generar calor. Ésta, a su vez, fue rebasada a finales del siglo xx por la lámpara led (siglas en inglés de "diodo fotoemisor"), que resulta diez veces más económica que la incandescente (además de ser fría) y tres veces más que la fluorescente. Y están por venir las lámparas láser domésticas...

Con todo este progreso, el Sol sigue siendo el rey: la iluminación artificial no sólo resulta incomparablemente más pobre y localizada, sino que se alimenta de energía que proviene... del Sol.

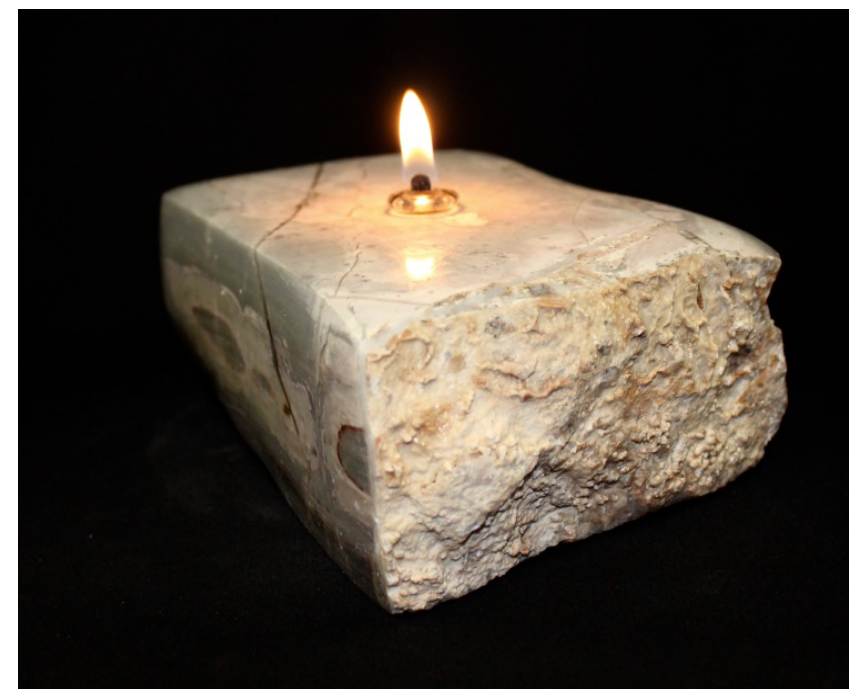

Con el paso de los siglos, mejoraron las formas de sustituir parcialmente al Sol. Al mismo tiempo, lo fuimos conociendo mejor a él y a la luz que nos regala. Por un lado, la astrofísica desentrañó el misterio de la fuente de energía que le da vida, descubriendo que se trata de una forma de energía nuclear que se libera al fusionarse núcleos de hidrógeno para producir núcleos de helio y convertirse, una parte ínfima de la masa nuclear, en radiación. El Sol nos alumbra comiéndose a sí mismo, como lo hace cualquier otra estrella viva. Hoy sabemos que nuestra estrella va a la mitad de su vida, así que le quedan aún cosa de seis mil millones de años para seguir iluminándonos.

Simultáneamente fuimos entendiendo el alma de la luz. Durante miles de siglos (la antigüedad del género Homo del que somos parte se estima en 2.5 millones de años) no supimos (quizá ni nos interesó saber) de que está hecha la luz. Sabemos desde hace poco más de 200 años la fórmula $\mathrm{H}_{2} \mathrm{O}$ del agua; así como la composición de esa mezcla principalmente de oxígeno y nitrógeno que es el aire. Y la luz, ¿de qué está hecha la luz? La respuesta que recibió esta pregunta en la antigüedad fue inocente: de luz. Se supuso, cuando finalmente surgió la pregunta, que la luz estaba compuesta de ínfimas particulitas de luz. Se requirió que transcurrieran siglos para que, cuando el siglo xvIII daba paso al xIx, el médico y científico inglés Thomas Young demostrara con un experimento definitivo que la luz no es una sustancia de naturaleza atómica como todo lo que

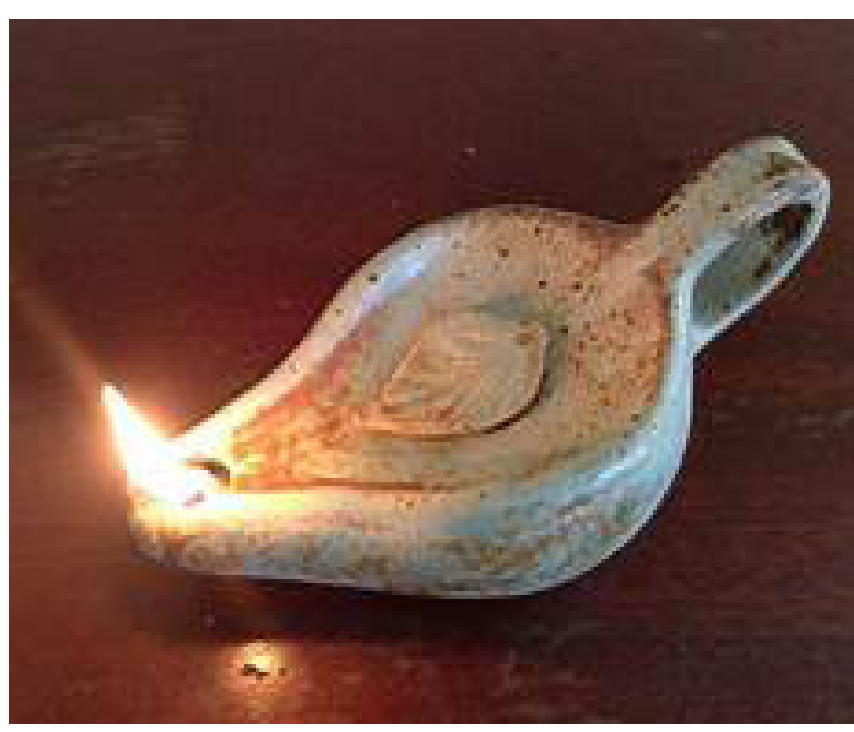


es una onda constituida por vibraciones eléctricas y magnéticas engarzadas entre sí de una manera muy específica. Las ondas electromagnéticas pueden tener cualquier frecuencia de vibración, y dependiendo del valor de ésta, constituyen ondas de radio, o microondas, o infrarrojas, o visibles, o ultravioletas, o rayos $\mathrm{X}$, o incluso rayos gamma (en orden creciente de frecuencia). El reducido intervalo de frecuencias que corresponde al espectro visible queda perdido entre el resto de bandas electromagnéticas, al centro de la lista, como se muestra en la figura 1; si no fuera por la enorme -inmensísima - importancia que tiene para nosotros, permanecería perdido, ya que sólo ocupa una región pequeñísima del espectro, apenas entre 400 y 750 nanómetros ( 1 nanómetros $=10^{-9}$ metros, o sea la millonésima parte de un milímetro). Esto representa una octava. En cambio, el oído humano registra 8-9 octavas sonoras.

El éter se entendió como el medio en que se propagan las ondas electromagnéticas en general, no sólo la luz. El espacio volvió a llenarse de éter, ahora aún más diluido y más elástico que en la antigüedad para ser capaz de soportar ondas transversales (vibraciones perpendiculares a la dirección de propagación) como son las electromagnéticas, sin ser arrastrado por el movimiento de la Tierra.

A partir de los trabajos de Maxwell y de otro gran científico británico, Michael Faraday, la teoría electromagnética y sus aplicaciones se desarrollaron con notable ímpetu. Este proceso dio lugar al surgimiento de la industria eléctrica y de comunicaciones, lo que vino a transformar de manera significativa y favorable nuestra forma de vida. En particular, al lado de la electricidad doméstica, urbana e industrial, apareció el radio, que representó en su momento el uso más importante y útil de las ondas electromagnéticas. El éter, que si existiera se nos deslizaría de las manos tan ligeramente como la luz, seguía siendo considerado el soporte de la radiación electromagnética, se tratara ahora de luz visible o invisible (radiofrecuencia u otra frecuencia).

Así entramos al siglo xx, en el que se construyen las dos grandes teorías físicas que lo caracterizan: la teoría de la relatividad y la teoría cuántica. Ambas teorías tuvieron mucho que decir sobre la luz. La naturaleza electromagnética de ésta no se alteró, pero adquirió un rostro diferente del que nos pintara la física clásica heredada del siglo xix. Por un lado, la teoría de la relatividad niega el éter, simplemente por no ser necesario, pues lo que vibra son precisamente las componentes eléctrica y magnética de la onda. Las ondas electromagnéticas son una forma de materia, aunque no se trata de materia atómica, como explicamos a continuación. El punto está en que las ondas electromagnéticas portan energía (energía electromagnética) y esta energía $E$ equivale a una masa $m$ dada por la más famosa fórmula de la física, $E=m c^{2}$ ( $c$ representa la velocidad de la luz en el vacío). Algo análogo sucede con la masa de la materia común (la materia atómica), pero la masa electromagnética no está constituida por átomos, sino por energía pura, radiante. Así, la luz propagándose representa energía que viaja por el espacio libre. No requiere éter para ello. 
Lo que acabamos de decir es parte de una de las más ricas ideas que produjo la física del siglo xIx, debida precisamente a Faraday y Maxwell: Ios fenómenos eléctricos o magnéticos que se dan en el espacio representan un fenómeno físico y energético real. Esto significa que hay algo físico en ese espacio. A ese algo eléctrico o magnético (o gravitacional, podemos agregar) distribuido en el espacio se le llama campo eléctrico o magnético o electromagnético (o gravitacional), según sea el caso. Estos campos son algo real, tan real como la materia atómica, pero de naturaleza enteramente diferente. Por ejemplo, el campo electromagnético es tan real que podemos ver o sentir una porción de él, cuando se trata de luz visible que alcanza nuestros ojos, o de radiación infrarroja que calienta (o quema) nuestra piel. Concluimos que el tejido del mundo está compuesto de materia (atómica) y de campos; descubrir esto y elaborarlo fue otra de las grandes contribuciones a nuestra comprensión de la naturaleza del mundo, y de la luz en particular. Debemos agregar a esto que en la actualidad está en discusión la naturaleza de inmensas regiones cósmicas (se estima que el 96\% del universo) que se consideran ocupadas por materia oscura y energía oscura. En este caso, con el calificativo oscuro se reconoce nuestra total ignorancia de su naturaleza: si se trata de algo conocido o novedoso es asunto del futuro.

La luz, pues, se propaga en el vacío. Resuelto esto, pasamos a la teoría cuántica, la que tuvo tantas cosas y tan radicales que decir sobre la luz, que conviene antes de entrar al tema aclarar a qué se refiere la mecánica cuántica. En breve (y de manera un tanto excluyente) podemos decir que la mecánica cuántica es la teoría física que debe aplicarse a los átomos y moléculas. Resulta ser una teoría muy rica, pero a la vez muy diferente de la física clásica. Por ejemplo, difiere de manera esencial de la mecánica (clásica) que conocemos por nuestra experiencia cotidiana. Una propiedad muy significativa de los sistemas cuánticos (electrones, protones, átomos, moléculas, etcétera) es que, al lado de sus propiedades como corpúsculos, poseen propiedades ondulatorias. Sucede en este caso lo opuesto a lo que sucedió a lo largo de los siglos con la luz: a ella se le consideró primero como corpuscular, y terminó siendo ondulatoria. A los átomos los consideramos (jdesde los griegos!) como corpúsculos, pero ahora debemos agregar que pueden comportarse (en ciertas condiciones) como una onda. La coexistencia de onda y corpúsculo es una peculiaridad universal de la mecánica cuántica. Desde esta perspectiva se nos podría ocurrir que el que ambas nociones hayan sido significativas para nuestra comprensión de la naturaleza de la luz no debe ser tan extraordinario, si acaso la teoría cuántica tiene algo que ver con la luz. Y sí, en efecto, así resultó: tiene mucho que ver y decir al respecto.

Es notable que el primer descubrimiento (en 1900) de un comportamiento cuántico se dio precisamente con la luz: la luz se reveló como un fenómeno con propiedades cuánticas. El calificativo cuántico se refiere aquí (y más en general) a que el intercambio de energía entre un campo electromagnético encerrado en una cavidad, y la cavidad que lo contiene (un horno, por ejemplo), se da por cantidades discretas. Esto es precisamente la idea que sugiere el término latino quantum, cantidad. La analogía más simple que viene a la mente es la del comer- 
cio contemporáneo: los productos molidos o granulados nos los venden en el supermercado en paquetes de uno, dos, cinco... kilos; y si se trata de líquidos, de uno, dos, cinco... litros; no podemos comprar siete gramos o 2.3 mililitros. A una conclusión similar llegó el físico alemán Max Planck después de insistentes esfuerzos por evitarla, pues la idea de "paquetes" (quanta) de luz de energía (fijada por su frecuencia) parecía descabellada. Pero los resultados experimentales lo obligaron a aceptarla, y pronto esta idea se convirtió en base para el estudio, primero de la luz, poco después de las propiedades cuánticas de la materia y, más tarde, de los campos en general. A estos paquetes de luz intercambiados se les conoce con el nombre de fotones.

Algunos años después (de 1905 a 1909) el joven Albert Einstein dio una interpretación más radical al fenómeno cuántico detectado en la luz (o sea en la radiación electromagnética, sea o no visible). Para Einstein, el comportamiento cuántico de la radiación se debe a que el propio campo electromagnético está organizado en cuantos de energía, o sea en paquetes independientes, fotones, cada uno con energía bien definida. Decir esto equivale a dotar al campo electromagnético (hasta entonces el paradigma de la continuidad) de una estructura corpuscular, discreta. Por su radicalidad, esta idea, aun proviniendo de Einstein (joven aún), tardó varios años en ser aceptada. Hoy en día, no sólo el campo electromagnético se concibe como compuesto por quanta, sino que a cualquier otro campo se le atribuyen también propiedades discretas. La visión heurística que sugiere esta descripción es simple: mientras se trata de un campo-digamos electromagnético para fijar ideas - de muy baja densidad, tal que dominan los procesos de interacción entre un fotón y un átomo, se requiere describir a este campo en términos discretos, es decir, cuánticos. Cuando, por lo contrario, se trata de un campo de alta densidad, donde interviene un enorme número de fotones, el fenómeno se nos manifiesta como un continuo, y debemos describirlo en los términos clásicos iniciales. La analogía con agua es inmediata: a escala molecular, el agua se manifiesta como una estructura discreta; a escala macroscópica (un vaso de agua, por ejemplo) se nos presenta como un continuo.

Parece conveniente insistir en la idea central: el lenguaje de los fotones es hoy universal; la luz nos llega a los ojos en torrentes que percibimos como clásicos. Pero en cantidades minúsculas es posible detectar los procesos discretos debidos a fotones individuales. La luz que vemos es concebida hoy, en conclusión, como formada por una plenitud de fotones; la cantidad mínima de luz que interacciona con un átomo aislado está formada, sin embargo, por un simple fotón, un paquetito de energía electromagnética que manifiesta su individualidad.

Terminemos regresando al principio, con la luz como un continuo. Quedó en el aire una pregunta: ¿y los colores?, ¿de dónde proceden? Fue siempre claro que el asunto de los colores atañe a la luz. Un recipiente de vidrio transparente azul pinta de azul su sombra, o de rojo si es rojo. Es claro: el color es luz. La primera clave firme de esto se debe a Newton, quien en su juventud estudió la luz, incluso escribió el más avanzado tratado sobre la luz hasta su época. Des- 
cubrió, entre tantas otras propiedades, que la luz blanca se descompone en un arcoíris al pasar por un prisma transparente. Y que, si al arcoíris así obtenido se le hace cruzar un segundo prisma transparente alineado con el primero, sale luz blanca nuevamente. Newton mostró con esto que la luz blanca está compuesta por luces de colores y la recombinación de ellos produce luz blanca.

Surge entonces la pregunta ¿cómo percibimos los colores? Los colores, como tales, no existen en la naturaleza; son una

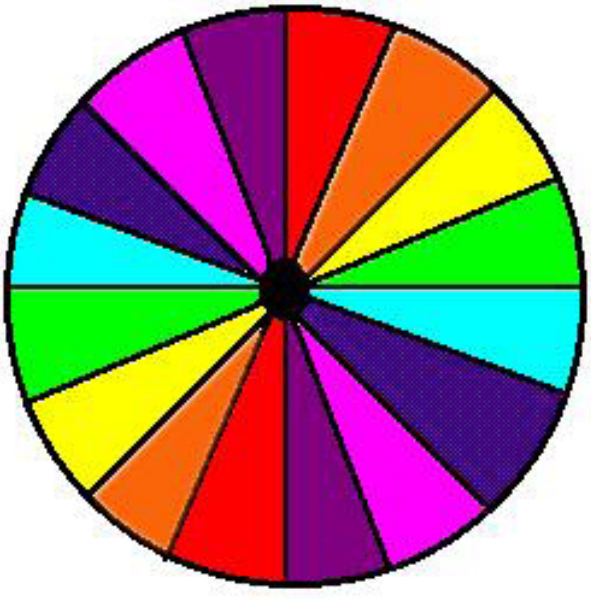
percepción construida por el cerebro a partir de la información que recibe de los ojos. Algo similar ocurre con los sonidos: lo que existe en la naturaleza son vibraciones (del aire o de los cuerpos); cuando tales vibraciones llegan a nuestros oídos producen impulsos nerviosos que el cerebro transforma, interpreta, como sonidos: a diferente frecuencia de vibración corresponde diferente tono. En el caso de la luz, a diferente frecuencia de la luz que incide en nuestros ojos, diferente color nos ofrece el cerebro. Así, tanto los sonidos como los colores son obra (jobra maestra!) de nuestro cerebro. Nuestro cerebro enriquece a la naturaleza.

Los millones de conos (células que reaccionan a la luz) que posee una región de la retina humana están especializados en distinguir con mayor eficiencia los colores rojo, verde o azul, que corresponden, respectivamente a las frecuencias menores, intermedias y mayores (o mayores, intermedias y menores longitudes de onda). A partir de estos tres colores el cerebro construye todos los colores que percibimos. Fue el mismo Thomas Young, descubridor del infrarrojo

Imágenes 6 y 7.

El experimento de Newton, según un artista y el disco de Newton se ve blanco al girar con rapidez.

Fuente: Smyth Academy

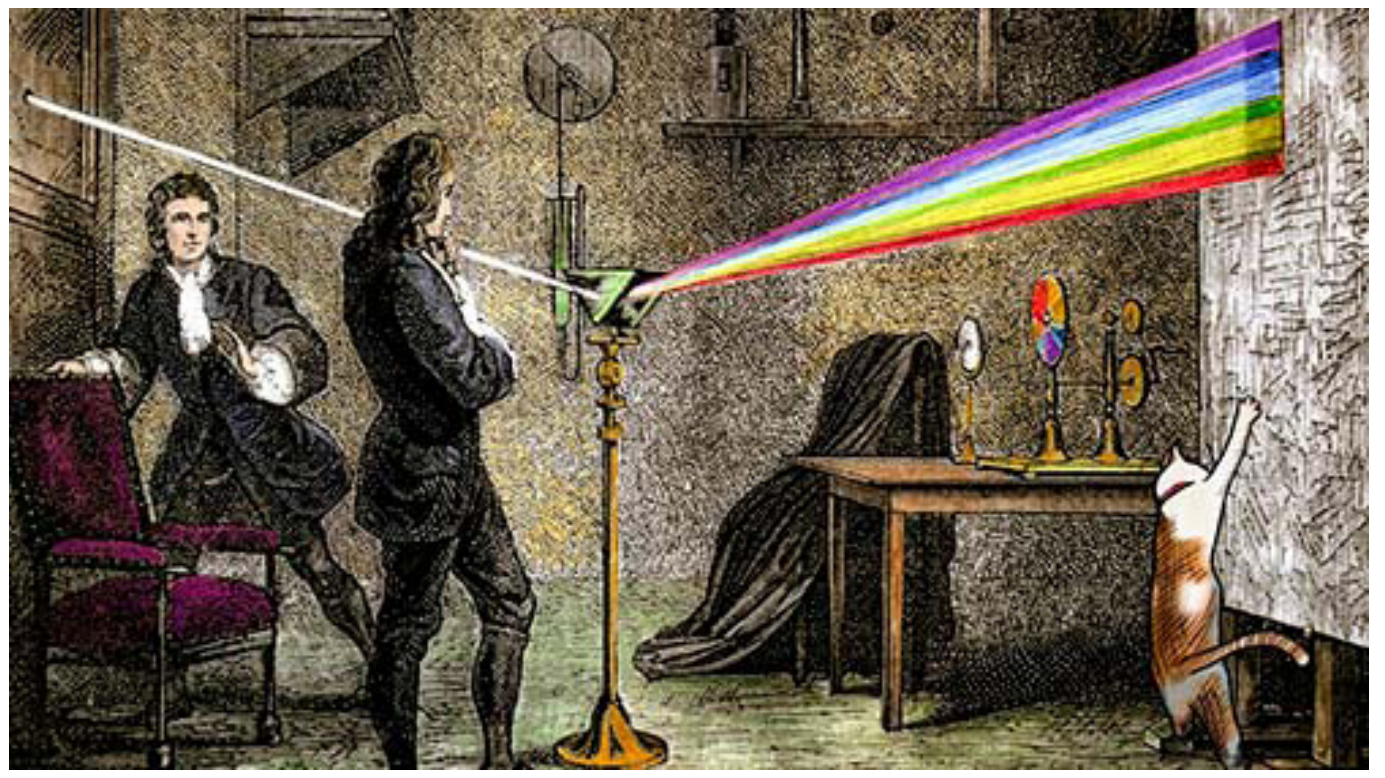


y que para ese entonces se había convertido en fisiólogo, quien propuso esta teoría de los tres colores. Antes de él la situación se percibía como sumamente compleja, pues se suponía que el cerebro respondía por separado a cada uno de los colores que percibimos, idea que da lugar a un galimatías.

El color que vemos de un objeto es el de la luz que refleja, no es una propiedad intrínseca del objeto. Los objetos no tienen color: se ven de color. Por esta razón, iluminando un objeto con luz de diversos colores, lo vemos de diverso color. La televisión aprovecha al máximo la suficiencia de tres colores para generar su variado colorido. Basta observar con una lente de aumento la pantalla del televisor para distinguir que cada uno de sus puntos luminosos está integrado por tres pequeñas fuentes de color. Normalmente se utiliza la combinación rojo, verde y azul, pero una impresora puede seguir otra regla. La prensa cotidiana y la imprenta a colores (y las impresoras caseras) aprovechan este fenómeno para generar la diversidad de colores, sólo que en la impresión la superposición de tintas es sustractiva (impide el reflejo): en este caso las tintas rojo, verde y azul mezcladas producen el color negro, es decir, el no color, que corresponde a la falta total de luz. Todo esto y mucho más se puede ver de manera atractiva en el Museo de la Luz de la unAm.

¿Podemos decir hoy que ya conocemos a cabalidad la luz? Ni tratándose de la luz ni de ningún otro asunto podemos decir que ya sabemos todo. Mucho hemos aprendido con el desarrollo de la ciencia y del conocimiento en general, lo que nos ha permitido aprender a hacer multitud de cosas, aparatos e instrumentos de toda índole. El Homo sapiens ha dejado muy atrás a sus lejanos antepasados con la ayuda de sus manos y su cerebro. Pero seguramente ignoramos mucho más de lo que sabemos. Esto incluye a la luz, naturalmente. Por ejemplo, uno de los más importantes problemas que se plantea la física actual es el de estructurar una nueva y avanzada teoría que combine exitosamente a las teorías de la relatividad y la cuántica. Pese al enorme esfuerzo invertido en este asunto, se trata de una tarea aún pendiente. Seguramente el esfuerzo que se realiza en torno al problema algún día dará el fruto buscado. Algo novedoso tendrá que decir la teoría resultante sobre muchas cosas, en particular respecto a la luz. Hoy no sabemos aún qué y cómo lo dirá. Pero de una cosa sí podemos estar seguros: tenemos todavía mucho que aprender; y esto vale tanto en el terreno de lo social como en el de lo natural.

\section{Referencias}

- Espectro electromagnético (s.f.). En Wikipedia. Recuperado el 15 de enero de 2018 de https://es.wikipedia.org/wiki/Espectro electromagn\%C3\%A9tico\#/media/File:Electromagnetic spectrumes.svg. 
Experimento de Young (s.f.). En Wikipedia. Recuperado el 15 de enero de 2018 de https://es.wikipedia.org/wiki/Experimento de Young

- Percepción del color (s.f.). En Wikipedia. Recuperado el 15 de enero de 2018 de https://es.wikipedia.org/wiki/Percepci\%C3\%B3n_del_color

- Navarrete Carrascosa, Rocío (s.f.). Teoría del color. ¿qué es el color? El color normalizado. Recuperado de https://gasparbecerra.files.wordpress.com/2008/11/historia-del-color4.pdf

* Homo heidelbergensis (s.f.). En Wikipedia. Recuperado el 15 de enero de 2018 de https://es.wikipedia.org/wiki/Homo_heidelbergensis

Para información sobre materia y energía oscuras ver el documental El Universo: Materia Oscura, Energía Oscura.

\section{Cómo citar este artículo}

* De la Peña, Luis (2018). La naturaleza de la luz. Revista Digital Universitaria (RDU). Vol. 19, núm. 3 mayo-junio. DOI: http://doi.org/10.22201/codeic.16076079e.2018. v19n3.a1. 